\title{
An endogenous factor enhances ferulic acid decarboxylation catalyzed by phenolic acid decarboxylase from Candida guilliermondii
}

\author{
Hui-Kai Huang ${ }^{1}$, Li-Fan Chen², Masamichi Tokashiki ${ }^{2}$, Tadahiro Ozawa ${ }^{3}$, Toki Taira ${ }^{2}$ and Susumu Ito ${ }^{2 *}$
}

\begin{abstract}
The gene for a eukaryotic phenolic acid decarboxylase of Candida guilliermondii was cloned, sequenced, and expressed in Escherichia coli for the first time. The structural gene contained an open reading frame of 504 bp, corresponding to 168 amino acids with a calculated molecular mass of 19,828 Da. The deduced amino sequence exhibited low similarity to those of functional phenolic acid decarboxylases previously reported from bacteria with 25-39\% identity and to those of PAD1 and FDC1 proteins from Saccharomyces cerevisiae with less than 14\% identity. The C. guilliermondii phenolic acid decarboxylase converted the main substrates ferulic acid and $p$ coumaric acid to the respective corresponding products. Surprisingly, the ultrafiltrate (Mr 10,000-cut-off) of the cellfree extract of $C$. guilliermondii remarkably activated the ferulic acid decarboxylation by the purified enzyme, whereas it was almost without effect on the $p$-coumaric acid decarboxylation. Gel-filtration chromatography of the ultrafiltrate suggested that an endogenous amino thiol-like compound with a molecular weight greater than $\mathrm{Mr}$ 1,400 was responsible for the activation.
\end{abstract}

Keywords: phenolic acid decarboxylase, ferulic acid decarboxylase, $p$-coumaric acid decarboxylase, Candida guilliermondii, activator

\section{Introduction}

Ferulic acid (FA), a derivative of 4-hydroxycinnamic acid, is found in cell walls primarily as an ester linked to lignin and other polysaccharides in cell walls, leaves and seeds of plants such as in rice, wheat, and oat [Mathew and Abraham 2004]. Bacterial phenolic acid decarboxylases (PADs), which decarboxylate FA, $p$-coumaric acid (PCA), and/or caffeic acid (CA) with concomitant production of 4-vinylguaiacol (4VG), 4-vinylphenol (4VP), and/or 4-vinylcatechol, respectively (see Additional file 1 ), are responsible for the detoxification of these 4hydroxycinnamic acids [Huang et al. 1994,Degrassi et al. 1995,Cavin et al. 1997b,1998]. [Zago et al. (1995)] first succeeded in sequencing and expression of a bacterial PAD (FA decarboxylase from Bacillus pumilus) in Escherichia coli. The genetic mechanism of bacterial PAD expression has been well established by the

\footnotetext{
*Correspondence: sito@agr.u-ryukyu.ac.jp

${ }^{2}$ Department of Bioscience and Biotechnology, University of the Ryukyus, Nishihara, Okinawa 903-0213, Japan

Full list of author information is available at the end of the article
}

discovery of PadR-mediated response to 4-hydroxycinnamic acids in Pediococcus pentosaceus [Barthelmebs et al. 2000], Bacillus subtilis [Tran et al. 2008], and Lactobacillus plantarum [Gury et al. 2009]. The 4VG formed is valuable precursor in the biotransformation of flavors and fragrances used in the food, pharmaceutical, and cosmetic industries [Mathew and Abraham 2006,Priefert et al. 2001]. Furthermore, this compound is sometimes present as an aroma in beers and wines [Thurston and Tubb 1981,Smit et al. 2003,Coghe et al. 2004,Oelofse et al. 2008,Sáez et al. 2010]

Naturally-occurring phenolic acids are known to inhibit the growth of yeasts such as Saccharomyces cerevisiae, Pichia anomala, Debaryomyces hansenii, and Candida guilliermondii (Meyerozyma guilliermondii comb. nov.; [Kurtzman and Suzuki 2010]) [Baranowski et al. 1980,Stead 1995,Pereira et al. 2011]. S. cerevisiae [Goodey and Tubb 1982,Clausen et al. 1994,Smit et al. 2003,Coghe et al. 2004], Brettanomyces bruxellensis [Godoy et al. 2008], and C. guilliermondii [Huang et al. 
2011] are suggested to produce a PAD in response or relation to 4-hydroxycinnamic acids.

Recently, we purified and characterized a highly active substrate-inducible PAD from C. guilliermondii ATCC 9058 (CgPAD) [Huang et al. 2011]. CgPAD is heatlabile, and its molecular mass determined by SDS-polyacrylamide gel electrophoresis is about $20 \mathrm{kDa}$, which is similar to those of yeast strains of Brettanomyces anomalus [Edlin et al. 1998] and B. bruxellensis [Godoy et al. 2008]. CgPAD was active toward 4-hydroxycinnamic acid derivatives, PCA, FA, and CA, whose relative activity ratios are different from the PADs of $B$. anomalus and B. bruxellensis.

In the case of C. guilliermondii ATCC 9058, CgPAD may be induced by both PCA and FA, because the ratios of decarboxylation activity toward FA to PCA in the cell-free extracts were comparable to that of the purified enzyme. However, 6-hydroxy-2-naphthoic acid (6H2N) induced CgPAD 20- and 6-fold greater than FA and PCA, respectively, and the ratios of decarboxylation activity toward FA to PCA in the cells grown on different carbon sources in the presence of the pseudo-inducer were found to be increased remarkably [Huang et al. 2011]. There was a possibility that $6 \mathrm{H} 2 \mathrm{~N}$ induced another FA decarboxylase distinct from CgPAD under a defined condition, but such activity was not detectable during the course of purification. In the present study, to resolve this inconsistency, we sequenced the gene for CgPAD and created recombinant enzymes. Unexpectedly, we found that the presence of dithiothreitol (DTT), 2-mercaptoethanol, cysteine, and homocysteine considerably accelerated the rates of FA decarboxylation activity of the purified native and recombinant CgPAD, while they did not affect those of their PCA decarboxylation activity. We also demonstrated that an unidentified amino thiol-like compound in the ultrafiltrate of the C. guilliermondii cell-free extract enhanced the FA decarboxylation activity specifically.

\section{Materials and methods Materials}

FA, CA, 4VG, and $6 \mathrm{H} 2 \mathrm{~N}$ were purchased from Wako Pure Chemical (Osaka, Japan). PCA was from MP Biomedicals (Solon, $\mathrm{OH}$ ), and 4VP was from Sigma-Aldrich (Steinheim, Germany). All other chemicals used were of analytical grade.

\section{Microorganisms and propagation}

The source of PAD and its gene was C. guilliermondii (M. guilliermondii) ATCC 9058. The enzyme was induced aerobically by $6 \mathrm{H} 2 \mathrm{~N}(1 \mathrm{mM})$ in Yeast Nitrogen Base (YNB; Invitrogen, Carlsbad, CA) broth containing $0.5 \%$ glucose as described [Huang et al. 2011]. Briefly, the yeast was grown at $25^{\circ} \mathrm{C}$ for $1 \mathrm{~d}$, with shaking, in 200-ml portions of the medium placed in 2-l flasks. $E$. coli DH5 $\alpha$ (Takara Bio, Otsu, Japan) and E. coli BL21 (DE3) (Takara Bio) were used for plasmid preparation and sequencing and for expression and purification of recombinant $\mathrm{CgPAD}$, respectively. The transformed $E$. coli cells were grown, with shaking, at $37^{\circ} \mathrm{C}$ in $50-\mathrm{ml}$ portions of Luria-Bertani broth plus ampicillin $(100 \mu \mathrm{g}$ $\mathrm{ml}^{-1}$ ) placed in $500-\mathrm{ml}$ flasks to an $A_{600}$ of 0.5 . After adding isopropyl $\beta$-D-galactosyl pyranoside $(0.1 \mathrm{mM})$ to the culture, incubations were further continued at $18^{\circ} \mathrm{C}$ for $24 \mathrm{~h}$. After cells were collected by centrifugation $(12,000 \times g$ for $10 \mathrm{~min})$ at $4^{\circ} \mathrm{C}$, cell pastes obtained from $600-\mathrm{ml}$ culture were used as the starting materials for enzyme purification.

\section{Purification of native and recombinant forms of CgPAD}

Enzyme purification was done at a temperature not exceeding $4^{\circ} \mathrm{C}$. The native CgPAD in C. guilliermondii was purified by successive column chromatographies on CM Toyopearl $650 \mathrm{M}$ (Tosoh, Tokyo, Japan), DEAE Toyopearl 650 M (Tosoh), and Bio-Gel P-100 (Bio-Rad, Hercules, CA) columns, as described previously [Huang et al. 2011].

The wild-type and mutant recombinant enzymes highly expressed in $E$. coli cells were each purified by essentially the same procedure as that of the native enzyme [Huang et al. 2011]. The recombinant E. coli cells were washed twice with saline and then suspended in two volumes of the extraction buffer [ $20 \mathrm{mM}$ sodium phosphate buffer ( $\mathrm{pH}$ 7.0) plus $1 \mathrm{mM}$ each of phenylmethanesulfonyl fluoride, $\mathrm{MgCl}_{2}$, EDTA, and DTT]. The cells were disrupted six times for $50 \mathrm{~s}$ each with glass beads $(0.5 \mathrm{~mm}$ in diameter) at 2,500 rpm in a homogenizer (Multi-Beads Shocker; Yasui Kikai, Osaka, Japan). After cell debris was removed by centrifugation $(12,000$ $\times g, 15 \mathrm{~min}$ ), the supernatant obtained was applied directly to a column of DEAE Toyopearl $650 \mathrm{M}(2.5 \mathrm{~cm}$ $\times 25.5 \mathrm{~cm}$ ) previously equilibrated with $20 \mathrm{mM} 2$-morpholinoethanesulfic acid/NaOH (MES) buffer ( $\mathrm{pH}$ 6.5). The column was initially washed with $200 \mathrm{ml}$ of $50 \mathrm{mM}$ $\mathrm{NaCl}$ in MES buffer ( $\mathrm{pH}$ 6.5), and proteins were eluted with a $300-\mathrm{ml}$ linear gradient of $50 \mathrm{mM}$ to $0.5 \mathrm{M} \mathrm{NaCl}$ in the buffer. The active fractions were immediately concentrated and exchanged with $50 \mathrm{mM}$ phosphate buffer ( $\mathrm{pH}$ 7.0) by ultrafiltration (Amicon Ultra-15; Millipore, Billerica, MA) to a small volume. The concentrate was then put on a column of Bio-Gel P-100 (1.0 $\mathrm{cm} \times 43 \mathrm{~cm}$ ) equilibrated with $50 \mathrm{mM}$ sodium phosphate buffer ( $\mathrm{pH}$ 7.0) and eluted with the equilibration buffer. The active fractions were combined and concentrated by ultrafiltration, and the concentrate was stored at $-20^{\circ} \mathrm{C}$ until use. Highly purified wild-type and mutant recombinant enzymes were obtained approximately 2to 5 -folds with yields of $40-70 \%$ within $2 \mathrm{~d}$ by the simple 
purification procedure as judged by SDS-acrylamide gel electrophoresis (see Additional file 2).

\section{Assay of CgPAD activity}

The enzyme assay method was essentially the same as described previously [Huang et al. 2011]. The initial velocity of decarboxylation activity was measured at $25^{\circ}$ $\mathrm{C}$ with 4-hydroxycinnamic acid as substrate. The reaction mixture contained the suitably-diluted enzyme solution and a $5 \mathrm{mM}$ substrate (neutralized with $1.0 \mathrm{~N}$ $\mathrm{NaOH}$ ) in $0.1 \mathrm{M}$ sodium phosphate buffer ( $\mathrm{pH}$ 6.0) in a final volume of $1.0 \mathrm{ml}$. After the reactions were terminated by boiling for $10 \mathrm{~min}$, the products formed were quantified by high-performance liquid chromatography (HPLC) using a packed column for reversed phase chromatography (Cosmosil 5C18-MS-II, $4.6 \mathrm{~mm} \times 150 \mathrm{~mm}$; Nacalai Tesque, Tokyo, Japan) with acetonitrile/0.05\% phosphoric acid $(7: 3, \mathrm{v} / \mathrm{v})$ as the mobile phase at a flow

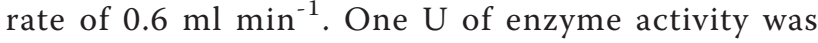
defined as the amount of enzyme that released $1 \mu \mathrm{mol}$ of $4 \mathrm{VG}$ or $4 \mathrm{VP}$ per min. Because the product, 4-vinylcatechol, from CA was not commercially available, the CA decarboxylation activity was expressed as formation of 4VG. Protein concentrations were measured using a BCA protein assay kit (Thermo Fisher Scientific, Rockville, MD) with bovine serum albumin as the standard.

\section{Sequencing of internal amino acid residues of CgPAD}

Initially, peptides of native CgPAD were obtained by treatment with $\mathrm{CNBr}$ or Staphylococcus aureus V8 protease. The $\mathrm{CNBr}$ cleavage was done essentially by the method of [Steers et al. (1965)]. One mg of CgPAD was dissolved in $0.2 \mathrm{ml}$ of $70 \%$ formic acid and cleaved with an excess of $\mathrm{CNBr}$ at room temperature for $24 \mathrm{~h}$. After the remaining $\mathrm{CNBr}$ was removed by a rotary evaporator, the reaction mixture was filtered on a column of TSK gel G2000SWXL (Tosoh, $0.78 \mathrm{~cm} \times 30 \mathrm{~cm}$ ) in $30 \%$ acetic acid. The digestion of CgPAD with V8 protease was performed at $37^{\circ} \mathrm{C}$ for $6 \mathrm{~h}$ in $50 \mathrm{mM}$ ammonium bicarbonate buffer ( $\mathrm{pH} 7.8$ ) plus $4 \mathrm{M}$ urea and $2 \mathrm{mM}$ EDTA. The peptide fragments obtained were fractionated by reverse-phase high-performance liquid chromatography on a C4 column $(3.9 \mathrm{~mm} \times 150 \mathrm{~mm}$, Waters, Milford, MA). The amino acid sequences of peptides derived from $\mathrm{CNBr}$ or $\mathrm{V} 8$ protease digestion of native CgPAD were determined by automated sequential Edman degradation using a PPSQ-23A protein sequencing system (Shimadzu, Kyoto, Japan).

\section{Cloning and sequencing of CgPAD gene}

All primers used are presented in Additional file 3. By a reverse transcription polymerase chain reaction using appropriate degenerate primers, the internal cDNA fragments of CgPAD were sequenced. Total RNA was isolated from C. guilliermondii using an RNeasy kit (Qiagen, Valencia, CA). First-strand cDNA synthesis was performed with $5 \mu \mathrm{g}$ of total RNA using a GeneRacer kit (Invitrogen, Carlsbad, CA) with oligo(dT) adaptor primer. The cDNA obtained was used as a template for PCR amplification with degenerate primers. The first PCR was performed with primers P1 (a forward primer designed from an internal LKNKHFQYTYDNGWKYEFHV) and P2 (a reverse primer designed from an internal AFSQGHWEHPEQAHGDKRED), and nested PCR was done with P1 and P3 (a reverse primer designed from an internal AFSQGHWEHPEQAHGDKRED) (the sequences used for primer design are underlined). The nested PCR product was then cloned into a pGEM-T vector (Promega, Madison, WI) and sequenced using the ABI Prism system (Model 310; Applied Biosystems, Foster City, CA).

To obtain the entire gene for CgPAD, both 5' and 3' rapid amplification of cDNA ends (RACE) were performed using a GeneRacer kit according to the manufacturer's instructions. The gene-specific primers $\mathrm{P} 4$ (first PCR) and P5 (nested PCR) were used for the 5'RACE and the gene-specific primers P6 (first PCR) and P7 (nested PCR) for the 3'-RACE. Approximately 250 bp and 290 bp were amplified by 5'-RACE and 3'-RACE, respectively. Finally, a cDNA fragment containing the entire coding region of CgPAD cDNA was amplified using the forward primer P8 (designed from the 5'RACE product) and reverse primer P9 (designed from the 3'-RACE product).

The nucleotide sequence of CgPAD was submitted to DDBJ under the accession number AB663499

\section{Site-directed mutagenesis}

The entire CgPAD gene was amplified by PCR and cloned into the NdeI/HindIII site of pET-22b (+) (Novagen, Darmstadt, Germany), yielding the construct designated pPAD22b. Amino acid replacements were performed using a QuikChange II site-directed mutagenesis kit (Stratagene, La Jolla, CA). PCR was performed using PfuUltra HF DNA polymerase (Promega) with pPAD22b as the template. The primer sets used were 5'-CATGGGGGGCCACTGGCTGGACGGCAC-3'/ 5'-GTGCCGTCCAGCCAGTGGCCCCCCATG-3' for the Met57 $\rightarrow$ Leu (M57L) mutation, 5'-CATGGGGGGCCAACGGCTGGACGGCAC-3'/5' -

GTACCGTCCAGCCGTTGGCCCCCCATG-3' for the M57T mutation, and 5'-CATGGGGGGCCAGCGGCTGGACGGCAC-3'/5'-

GTGCCGTCCAGCCGCTGGCCCCCCATG-3' for the M57A mutation (the underlined sequences indicate mutated codons). To express mutant proteins, the 
resulting plasmids harboring the respective mutated genes were each introduced into competent $E$. coli BL21 (DE3) cells.

\section{Construction of model structure of CgPAD}

The secondary structure of CgPAD was predicted by the method of [Kabsch and Sander (1983)]. The deduced amino acid sequence of the enzyme was aligned with that of the crystal structure of a PAD (PCA decarboxylase) from $L$. plantarum (LPPAD; PDB code 2GC9) [Rodríguez et al. 2010]. A model of the CgPAD structure built with method of homology modeling was constructed based on the structure of LPPAD [Sali et al. 1993]. All data sets were processed on a Windows XP personal computer using the Discovery Studio software package (Accelrys, San Diego, CA). Distance between intramolecular sulfur atom of methionine and side-chain carbonyl oxygen atoms of glutamic acid or amide nitrogen atom of arginine was calculated from the coordinate values. The figure was prepared using a DS Visualizer (Accelrys).

\section{Results}

Nucleotide and deduced amino acid sequences of CgPAD We initially cloned and sequenced the CgPAD gene. The entire CgPAD gene was 504 nucleotides in length, and an open reading frame encoded 168 amino acid residues (Figure 1). The calculated molecular mass was 19,828 Da http://web.expasy.org/compute_pi/, a value very close to the $20 \mathrm{kDa}$ determined for the native enzyme by SDS-polyacrylamide gel electrophoresis [Huang et al. 2011].

The deduced amino acid sequence of CgPAD was aligned with those of functional PADs reported to date from different bacteria [Thompson et al. 1997]; http:// www.genome.jp/tools/clustalw). As shown in Figure 2, CgPAD exhibited very low similarity of sequence to functional PADs reported to date from L. plantarum WCFS1 ([Rodríguez et al. 2010] and L. plantarum LPCHL2 [Cavin et al. 1997a] with 39\%, Enterobacter sp. Px6-4 [Gu et al. 2011a,2011b] with 34\%, Klebsiella oxytoca [Uchiyama et al. 2008] with $27 \%$, and B. subtilis 168 [Cavin et al. 1998] with 26\% identity, and B. pumilus PS213 [Zago et al.1995], P. pentosaceus ATCC 25745 [Barthelmebs et al. 2000], and Lactobacillus brevis ATCC 367 (RM84) [Landete et al. 2010] each with 25\% identity. Nevertheless, four residues (Tyr18, Tyr20, Arg48, and Glu71) involved in the catalysis of LpPAD [Rodríguez et al. 2010] were well conserved in CgPAD as Tyr30, Tyr32, Arg60 [but Asn23 in the Enterobacter enzyme [Gu et al. 2011b]], and Glu82 and of PADs from other bacteria as these residues at the corresponding positions.

\section{Construction of model structure and creation of mutant proteins of CgPAD}

The absence and/or replacement of methionine residues adjacent to catalytic residues or in the proximate area of active-site pockets has been reported to confer resistance to oxidation, as based on the catalytic activity of enzymes [Estell et al. 1985, Hagihara et al. 2001,2003, Nonaka et al. 2003]. Further, we demonstrated that the replacement or oxidation of such the Met residues altered the conversion rates of substrates by some enzymes [Hagihara et al. 2001,2003, Nonaka et al. 2003,2004,Saeki et al. 2007]. Then, we first postulated that the fluctuation of the ratio of decarboxylation toward FA to PCA might result from oxidation of heatlabile CgPAD, because the deduced amino acid sequence contained two oxidizable Met residues at positions 57 and 103 (Figure 1). It was expected that the replacement of either Met57 or Met 103 with the nonoxidizable amino acids would increase the ratio of decarboxylation activity of CgPAD toward FA to PCA.

According to this scenario, we constructed a model of CgPAD using the crystal structure of LpPAD (PDB code 2GC9) as the template. In the result, the Met residues at positions 57 and 103 in the modeled CgPAD appeared to be located in the active-site pocket (see Additional file 4). Especially, the Met57 residue is located at the entrance of the pocket and in the immediate vicinity of possible catalytic residues Arg60 and Glu82. However, the Met103 residue is spatially more distant from the two catalytic residues and located deeper in the active-site pocket (see Additional file 5).

Therefore, we selected the Met57 residue as the target for site-directed mutagenesis and created the mutant enzymes with M57L, M57T, and M57A. The recombinant wild-type and mutant enzymes expressed in E. coli cells, together with the native enzyme from C. guilliermondii, were each purified to homogeneity (see Additional file 2). Contrary to our expectation, a mutant enzyme with M57L did not increase the ratio of decarboxylation activity of CgPAD toward FA to PCA compared with the native and recombinant wild-type enzymes, as shown in Table 1 . The activities toward both substrates of the mutants with M57T and M57A were practically negligible.

\section{Acceleration of FA decarboxylation activity of CgPAD by thiol compounds}

For measurement of enzyme activities in the cell-free extracts, we disrupted the cells in the extraction buffer supplemented with $1 \mathrm{mM}$ DTT. Then, we examined the effect of this thiol on the activity of purified native CgPAD. As the result, the FA decarboxylation activity was found to be enhanced by DTT at $0.2-1 \mathrm{mM}$ (Figure 
3), while the PCA decarboxylation activity was not affected by DTT at the concentrations examined.

To further understand the unexpected positive effect of DTT, we examined the effects of various thiol-containing amino acids and chemical reagents on both activities. Positive effects on the FA decarboxylation activity were also observed with 2-mercaptoethanol (5 $\mathrm{mM}$ ) and sulfhydryl amino acids such as L-cysteine, Dcysteine, and DL-homocysteine (1 $\mathrm{mM}$ each), and the increases in the relative decarboxylation activities of FA to PCA reached 2:1 to 3:1 when compared with the control (without thiol), as shown in Table 2. Cysteic acid (1 $\mathrm{mM}$ ) was essentially without effect.

The possibility that the replacement of Met57 with leucine disrupted the structural proper folding of CgPAD was not excluded because its specific activity was considerably lower than those of the native and wild-type enzymes (Table 1). However, the positive effect by L-cysteine (1 $\mathrm{mM})$ on FA decarboxylation activity was also observed with the M57L mutant enzyme as well as with native and recombinant wildtype forms, as shown in Table 3. Essentially, L-cysteine was without effect on the decarboxylation activity toward CA of the wild-type enzyme. The activity toward CA of the M57L mutant enzyme was too low to evaluate the effect of L-cysteine.

\section{Activation of FA decarboxylation activity by ultrafiltrate of cell-free extract}

Finally, we supposed that C. guilliermondii inherently possessed a physiological thiol activator, which might have been removed during the enzyme purification. Then, we prepared an ultrafiltrate of the cell-free extract (Mr 10,000-cut-off) of induced C. guilliermondii cells 


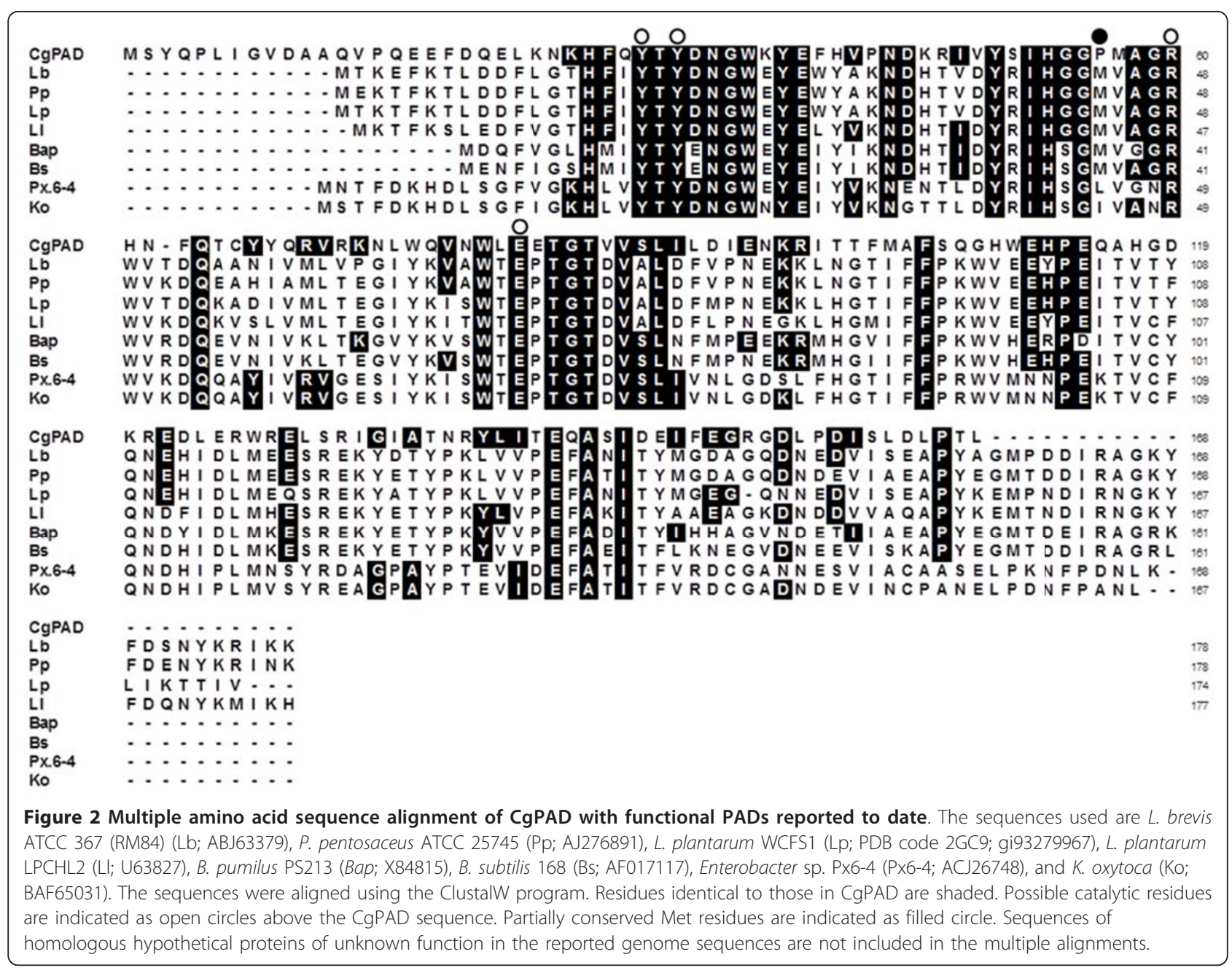

and incubated it with native and recombinant CgPADs at $25^{\circ} \mathrm{C}$ for $20 \mathrm{~min}$ before enzyme assays. As the results shown in Figure 4, the ultrafiltrate was found to remarkably increase the FA decarboxylation activities of both enzymes (approximately up to 5 -folds) with an increase in its volume, while it exhibited little effect on their PCA and CA decarboxylation activities. The ultrafiltrate of the cell-free extract of recombinant $E$. coli did not exhibit such an activation effect.

Partial purification of true activator in the ultrafiltrate The ultrafiltrate was subjected to gel-filtration chromatography on Bio-Gel P-2. As shown in Figure 5, a possible true activator associated with the FA decarboxylation activity was detected in fractions corresponding to a $\mathrm{Mr}$ larger than 1,400. The fractions reacted positively with the 5,5'-dithio-bis(2-nitrobenzoic acid) (DTNB) and ninhydrin reagents. In the presence of $50 \mu \mathrm{l}$ of the filtrate, the values of $K_{\mathrm{m}}, k_{\mathrm{cat}}$, and $k_{\text {cat }} /$ $K_{\mathrm{m}}$ for FA were $5.67 \mathrm{mM}, 278 \mathrm{~s}^{-1}$, and $49.0 \mathrm{~s}^{-1} \mathrm{mM}^{-1}$, whereas those of the control (without filtrate) were 5.31 $\mathrm{mM}, 89.7 \mathrm{~s}^{-1}$, and $16.9 \mathrm{~s}^{-1} \mathrm{mM}^{-1}$, respectively.

\section{Discussion}

This study describes for the first time the cloning, sequencing, and expressing the gene for a eukaryotic PAD in E. coli. CgPAD exhibited very low sequence similarity to reported functional PADs with 24-39\% identity. CgPAD showed $100 \%$ amino acid sequence identity to a hypothetical protein (EDK35930; locus tag PGUG_00028) in the genome of the yeast $M$. guilliermondii ATCC 6260 (AAFM00000000), and moderate similarity (51-56\% identity) to the internal sequences of hypothetical proteins of unknown function in the genomes of fungi including the genera Verticillium, Neosartorya, Aspergillus, Schizophyllum, Ustilago, Sporisorium, Nectria, Gibberella, and Penicillium (data not shown). Notably, CgPAD exhibited sequence similarity to PAD1 (YDR538W) with less than 14\% identity and essentially no homology with FDC1 (YDR539W) 
Table 1 Substrate specificities of native and recombinant enzymes

\begin{tabular}{|c|c|c|c|}
\hline Enzyme & Substrate & $\begin{array}{c}\text { Specific activity } \\
\left(\mathrm{U} \mathrm{mg}^{-1}\right)\end{array}$ & $\begin{array}{c}\text { Relative activity }{ }^{\text {a }} \\
(\%)\end{array}$ \\
\hline \multirow[t]{3}{*}{ Native } & FA & $378 \pm 16$ & 100 \\
\hline & PCA & $393 \pm 6$ & 104 \\
\hline & CA & $53 \pm 9$ & 14 \\
\hline \multirow[t]{16}{*}{ Recombinant } & Wild-type & & \\
\hline & FA & $260 \pm 30$ & 100 \\
\hline & PCA & $259 \pm 4.0$ & 100 \\
\hline & CA & $31.7 \pm 2.8$ & 12 \\
\hline & M57L & & \\
\hline & FA & $20.1 \pm 0.3$ & 100 \\
\hline & PCA & $20.5 \pm 0.3$ & 102 \\
\hline & CA & $2.93 \pm 0.03$ & 15 \\
\hline & M57T & & \\
\hline & FA & $<0.1$ & - \\
\hline & PCA & $<0.1$ & - \\
\hline & CA & $<0.01$ & - \\
\hline & M57A & & \\
\hline & FA & $<1.0$ & - \\
\hline & PCA & $<1.0$ & - \\
\hline & $C A$ & $<0.02$ & - \\
\hline
\end{tabular}

${ }^{a}$ The FA decarboxylation activities of the native and recombinant enzymes are taken as $100 \%$ for each.

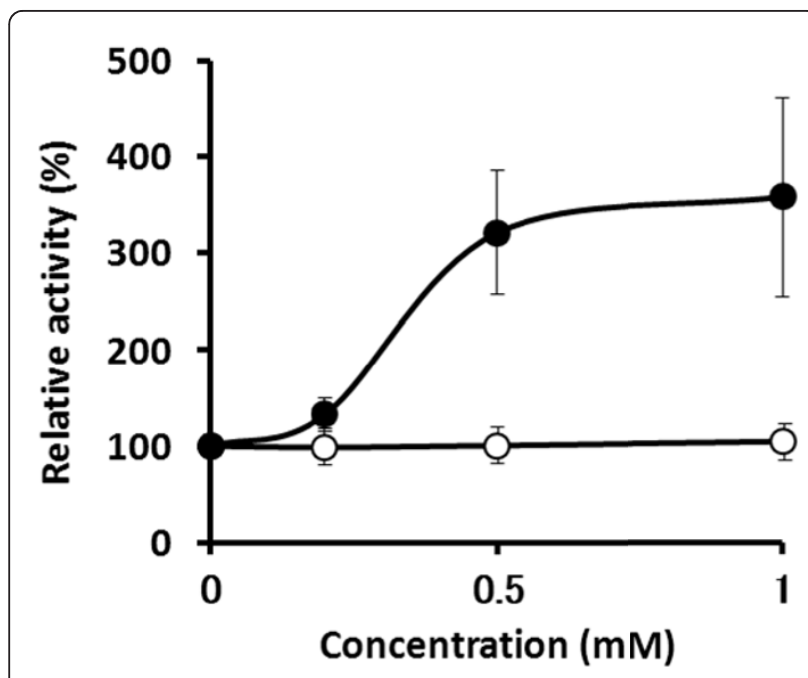

Figure 3 Effect of DTT on decarboxylation activities toward FA and PCA of purified native CgPAD. DTT $(0.2,0.5$, or $1 \mathrm{mM})$ was added to the reaction mixtures containing $\times 10$ enzyme $(1.0-\mathrm{ml}$ final volume) and incubated at $25^{\circ} \mathrm{C}$ for $20 \mathrm{~min}$. An aliquot $(0.1 \mathrm{ml})$ was withdrawn and added to $0.9 \mathrm{ml}$ of the reaction mixture containing 0.1 M FA or PCA, and the initial velocities of decarboxylation of FA (filled circle) and PCA (open circle) were measured under the standard conditions of enzyme assay. The values obtained from three separate experiments are shown and expressed as percentages, taking the activity of each untreated enzyme as 100\%. The bars indicate the standard deviation at each point.
Table 2 Effects of thiol reagents on the activities of native CgPAD

\begin{tabular}{cccc}
\hline \multirow{2}{*}{ Additive (1 mM) } & \multicolumn{2}{c}{ Specific activity $\left(\mathbf{U ~ \mathbf { ~ m } ^ { - 1 } )}\right.$} & \multirow{2}{*}{ FA/PCA } \\
\cline { 2 - 3 } & FA (\%) & PCA (\%) & \\
\hline None & $378 \pm 16(100)$ & $393 \pm 6(100)$ & 0.96 \\
2-Mercaptoethanol (5 mM) & $806 \pm 56(213)$ & $440 \pm 3(112)$ & 1.83 \\
Dithiothreitol & $1140 \pm 177(302)$ & $598 \pm 7(112)$ & 1.91 \\
L-Cysteine & $1130 \pm 37(299)$ & $437 \pm 39(111)$ & 2.59 \\
D-Cysteine & $1590 \pm 252(421)$ & $590 \pm 4(150)$ & 2.69 \\
DL-Homocysteine & $1830 \pm 354(484)$ & $628 \pm 9(160)$ & 2.91 \\
Cysteic acid & $557 \pm 30(147)$ & $593 \pm 9(151)$ & 0.94 \\
\hline
\end{tabular}

Experimental conditions were the same as those described in Figure 3.

isolated from S. cerevisiae [Clausen et al. 1994,Mukai et al. 2010].

There was a possibility that either Met57 or Met103 in CgPAD was located in the active-site pocket and oxidized to methionine sulfoxide during growth or purification. Accordingly, the massive sulfoxide group of the oxidized Met residue in the CgPAD might hinder the entry of FA (4-hydroxy-3-methoxycinnamic acid) due to its 3-methoxy group, but not PCA (4-hydroxycinnamic acid), to the active-site pocket. To understand the fluctuation of the ratio of decarboxylation toward FA to PCA of CgPAD, we constructed a model structure of the enzyme and replaced the Met57 residue located at the entrance of the pocket with non-oxidizable amino acids by site-directed mutagenesis. However, a mutant enzyme (M57L) did not increase the decarboxylation ratio of FA to PCA, for instance. This may exclude the possibility that oxidation of Met57, close to the catalytic residues Arg60 and Glu82, alters the decarboxylation

Table 3 Effect of L-cysteine on the activities of recombinant wild-type and M57L mutant CgPAD

\begin{tabular}{ccc}
\hline Substrate & Specific activity $\left(\mathbf{U ~ m g}^{-1}\right)$ & Relative activity $^{\mathbf{b}}(\mathbf{\%})$ \\
\hline Wild type & & \\
FA & $260 \pm 9.0$ & 100 \\
FA + L-cysteine ${ }^{a}$ & $759 \pm 156$ & 292 \\
PCA & $259 \pm 4.0$ & 100 \\
PCA + L-cysteine & $257 \pm 3.3$ & 99 \\
CA & $31.7 \pm 2.8$ & 12 \\
CA + L-cysteine & $35.9 \pm 3.5$ & 14 \\
M57L & & \\
FA & $20.1 \pm 0.3$ & 100 \\
FA + L-cysteine ${ }^{a}$ & $66.7 \pm 8.5$ & 332 \\
PCA & $20.5 \pm 0.3$ & 100 \\
PCA + L-cysteine & $26.0 \pm 2.7$ & 127 \\
CA & $<2.6$ & $<13$ \\
CA + L-cysteine & ND ${ }^{c}$ & \\
\hline
\end{tabular}

Experimental conditions were the same as those described in Figure 3. ${ }^{\text {a }}$ Treated with $1 \mathrm{mM}$. ${ }^{\mathrm{b}}$ The activity toward FA is taken as $100 \%$. ${ }^{c}$ Not determined. 


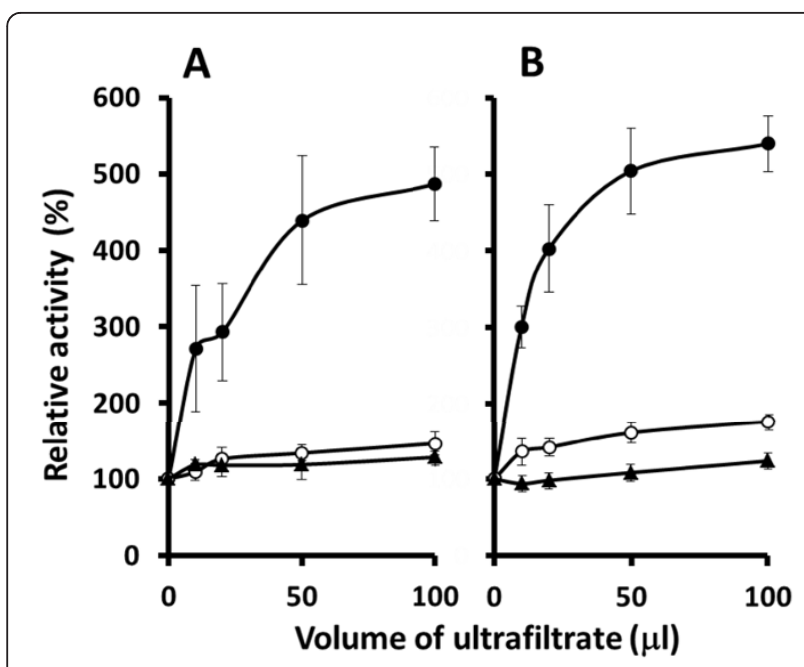

Figure 4 Effect of ultrafiltrate on activities of native (A) and recombinant wild-type CgPAD (B). Cell pastes of $6 \mathrm{H} 2 \mathrm{~N}$-induced $C$. guilliermondii and recombinant $E$. coli were disrupted with glass beads in the extraction buffer. The fresh cell-free extracts obtained (5.8-7.5 $\mathrm{mg}$ protein $\mathrm{ml}^{-1}$ ) were ultrafiltered by centrifugation in an Amicon Ultra-15. Aliquots $(10 \mu \mathrm{l}$ to $100 \mu \mathrm{l})$ of the ultrafiltrate were added immediately to the reaction mixture containing enzyme (0.95- $\mathrm{ml}$ final volume), incubated at $25^{\circ} \mathrm{C}$ for $20 \mathrm{~min}$, and then the initial velocities toward substrates were measured by adding $50 \mu \mathrm{l}$ of a $0.1 \mathrm{M}$ substrate. The values were obtained from several separate experiments and are expressed as percentages, taking the activity toward FA (filled circle), PCA (open circle), and CA (filled triangle) of the untreated enzyme as $100 \%$.

ratio of FA to PCA. A single Cys residue at position 66 could be responsible for the alteration of CgPAD activity. However, in the model of CgPAD we built, the Cys66 residue is located deeper in the active-site pocket and faced on the other side and far distant $(7.2 \AA)$ from the indole ring of $\operatorname{Trp} 80$ which might interact with Glu82 (data not shown). Essentially, conversion of cysteine to cysteic acid during purification steps is unlikely because cysteine is oxidized by strong chemical oxidants.

In this study, the activities toward substrates of the M57T and M57A mutants, together with M57L mutant, were found to be much lower than those of the native and recombinant wild-type forms of CgPAD. This result suggests that Met57 is one of the substrate-binding residues in the catalysis of CgPAD. In support of our view, one of substrate-binding residues, Leu45, in the Enterobacter PAD [Gu et al. 2011b] is conserved as Met at the corresponding positions in the aligned bacterial enzymes. The corresponding residue in CgPAD is Met57 in the model structure of CgPAD (see Additional file 4).

Unexpectedly, we found that the rate of FA decarboxylation activity, but not PCA decarboxylation activity, of CgPAD was accelerated by DTT, 2-mercaptoethanol,

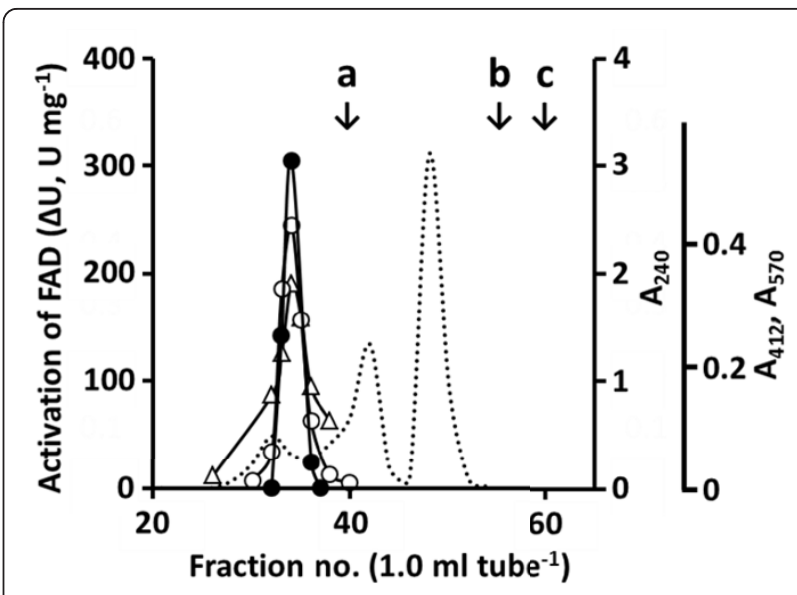

Figure 5 Gel-filtration chromatography of ultrafiltrate. One $\mathrm{ml}$ of the ultrafiltrate prepared from the cell-free extract of induced $C$. guilliermondii cells was applied to a Bio-Gel P-2 column $(1.0 \mathrm{~cm} \times$ $50 \mathrm{~cm}$ ) previously washed with distilled water and eluted with distilled water. The column was calibrated with cyanocobalamin (a, $M r=1,355)$, cellobiose $(b, M r=342)$, and glucose $(c, M r=180)$, as indicated by vertical arrows. The elution pattern was monitored by measuring at $240 \mathrm{~nm}$ (dotted line). The fractions containing the activator of FAD activity (filled circle) were examined for color reactions with DTNB solution at $412 \mathrm{~nm}$ (open circle) and ninhydrin solution at $570 \mathrm{~nm}$ (open triangle). The activation was expressed as $\Delta \mathrm{U} \mathrm{mg}{ }^{-1}$ [(activity + eluate)-(control activity)] after 20-min incubation at $25^{\circ} \mathrm{C}$. For the color reactions, $0.1-\mathrm{ml}$ aliquots were added to 0.9 $\mathrm{ml}$ of $5 \mathrm{mM}$ DTNB in $50 \mathrm{mM}$ phosphate buffer ( $\mathrm{pH} 7.5)$ and ninhydrin solution, respectively.

cysteine (both L- and D-forms), and DL-homocysteine, which are antioxidants and/or reducing reagents. However, these chemical reagents cannot reduce oxidized Met residues (methionine sulfoxide and methionine sulfonate) in protein molecules. Furthermore, L-cysteine and L-homocysteine are involved in the trans-sulfurization of amino acid metabolism (e.g., [Brosnan and Brosnan 2006]), both of which intracellular concentrations are very lowered by strict regulatory control. These results exclude the possibility that these amino acids are the physiological activator for CgPAD.

Finally, we found that an amino thiol-like endogenous factor in the ultrafiltrate of the C. guilliermondii cellfree extract drastically enhanced the FA decarboxylation activity. The kinetic data indicate that the ultrafiltrate increases the maximal activity toward FA without altering of the affinity to the substrate. These findings led us to conclude that a true activator for FA decarboxylation activity is inherently present in the C. guilliermondii cells. This also shows that the true activator was removed during the enzyme purification. Such a catalytic nature has never been reported in the literature. Identification of the structure of the endogenous activator would explain the novel catalytic feature of CgPAD and contribute to the clarification of physiological role 
of PADs in some yeast cells. It is interesting to examine whether such activation of eukaryotic PADs is observed by ultrafiltrates of prokaryotes and vice versa.

[Rodríguez et al. (2010)] clarified by site-directed mutagenesis of Arg48 and Glu71 in LPPAD that the entrance region, particularly the $\beta 1-\beta 2$ and $\beta 3-\beta 4$ loops, adopted a distinct closed conformation that decreased the opening of the active-site cavity. Possible subsite residues Tyr30 and Tyr32 and catalytic residue Glu82 along with Met57 of CgPAD are located on the $\beta 1-\beta 2$ loop and $\beta 3-\beta 4$ loop, respectively (see Additional file 4 A). It is possible that the physiological activator in the ultrafiltrate and/or the tested thiol compounds induce conformational change of the loops so that the entry of FA is much easier than those of PCA and CA. CgPAD exhibits low sequence similarity to LPPAD of known structure, and we are now crystalizing CgPAD to solve its X-ray structure.

\section{Additional material}

\section{Additional file 1: Reaction scheme for CgPAD with different} substrates. Supplementary scheme 1.

Additional file 2: SDS-polyacrylamide gel electrophoresis of purified enzymes. Supplementary figure 1.

Additional file 3: Primers for CgPAD cDNA cloning. Supplementary table 1.

Additional file 4: A. Structure-based amino acid sequence alignment of CgPAD with LpPAD of known structure (PDB code 2GC9). B. A model structure of CgPAD incorporating possible catalytic residues Glu82 and Arg60 residues and subsite residues Tyr30 and Tyr32, along with Met57 and Cys66. Supplementary figure 2.

Additional file 5: A. A CPK model of CgPAD. B. Coordination of the catalytic residues in the surrounding Met57 (upper) and Met103 (lower) in the model CgPAD structure. Supplementary figure 3.

\begin{abstract}
Author details
'United Graduate School of Agricultural Sciences, Kagoshima University, Kagoshima, Kagoshima 890-0065, Japan ²Department of Bioscience and Biotechnology, University of the Ryukyus, Nishihara, Okinawa 903-0213, Japan ${ }^{3}$ Tochigi Research Laboratories of Kao Corporation, Ichikai, Haga, Tochigi 321-3497, Japan
\end{abstract}

\section{Competing interests}

The authors declare that they have no competing interests.

Received: 23 November 2011 Accepted: 4 January 2012

Published: 4 January 2012

\section{References}

Baranowski JD, Davidson PM, Nagel CW, Branen AL (1980) Inhibition of Saccharomyces cerevisiae by naturally occurring hydroxycinnamates. J Food Sci 45:592-594. doi:10.1111/j.1365-2621.1980.tb04107.x.

Barthelmebs L, Lecomte B, Diviès C, Cavin JF (2000) Inducible metabolism of phenolic acids in Pediococcus pentosaceus is encoded by an autoregulated operon which involves a new class of negative transcriptional regulator. J Bacteriol 182:6724-6731. doi:10.1128/JB.182.23.6724-6731.2000.

Brosnan JT, Brosnan ME (2006) The sulfur-containing amino acids: an overview. J Nutr 136:1636S-1640S
Cavin JF, Barthelmebs L, Diviès C (1997a) Molecular characterization of an inducible $p$-coumaric acid decarboxylase from Lactobacillus plantarum: gene cloning, transcriptional analysis, overexpression in Escherichia coli, purification and characterization. Appl Environ Microbiol 63:1939-1944

Cavin JF, Barthelmebs L, Guzzo J, Beeumen JV, Samyn B, Travers JF, Diviès C (1997b) Purification and characterization of an inducible $p$-coumaric acid decarboxylase from Lactobacillus plantarum. FEMS Microbiol Lett 147:291-295. doi:10.1111/j.1574-6968.1997.tb10256.x.

Cavin JF, Dartois V, Diviès C (1998) Gene cloning, transcriptional analysis, purification, and characterization of phenolic acid decarboxylase from Bacillus subtilis. Appl Environ Microbiol 64:1466-1471

Clausen M, Lamb CJ, Megnet R, Doerner PW (1994) PAD1 encodes phenylacrylic acid decarboxylase which confers resistance to cinnamic acid in Saccharomyces cerevisiae. Gene 142:107-112. doi:10.1016/0378-1119(94)903638.

Coghe S, Benoot K, Delvaux F, Vanderhaegen B, Delvaux FR (2004) Ferulic acid release and 4-vinylguaiacol formation during brewing and fermentation: indications for feruloyl esterase activity in Saccharomyces cerevisiae. J Agric Food Chem 52:602-608. doi:10.1021/jf0346556.

Degrassi G, Polverino de Laureto P, Bruschi CV (1995) Purification and characterization of ferulate and p-coumarate decarboxylase from Bacillus pumilus. Appl Environ Microbiol 61:326-332

Edlin DAN, Narbad A, Gasson MJ, Dickinson JR, Lloyd D (1998) Purification and characterization of hydroxycinnamate decarboxylase from Brettanomyces anomalus. Enzyme Microb Technol 22:232-239. doi:10.1016/S0141-0229(97) 00169-5.

Estell DA, Graycar TP, Wells JA (1985) Engineering an enzyme by site-directed mutagenesis to be resistant to chemical oxidation. J Biol Chem 260:6518-6521

Godoy L, Martínez C, Carrasco N, Ganga MA (2008) Purification and characterization of a $p$-coumarate decarboxylase and a vinylphenol reductase from Brettanomyces bruxellensis. Int J Food Microbiol 127:6-11. doi:10.1016/j. ijfoodmicro.2008.05.011.

Goodey AR, Tubb RS (1982) Genetic and biochemical analysis of the ability of Saccharomyces cerevisiae to decarboxylate cinnamic acids. J Gen Microbiol 128:2615-2620

Gu W, Li X, Huang J, Duan Y, Meng Z, Zhang KQ, Yang J (2011a) Cloning, sequencing, and overexpression in Escherichia coli of the Enterobacter sp. Px6-4 gene for ferulic acid decarboxylase. Appl Microbiol Biotechnol 89:1797-1805. doi:10.1007/s00253-010-2978-4.

Gu W, Yang J, Lou Z, Liang L, Sun Y, Huang J, Li X, Cao Y, Meng Z, Zhang KQ (2011b) Structural basis of enzymatic activity for the ferulic acid decarboxylase (FADase) from Enterobacter sp. Px6-4. PLoS ONE 6(1):e16262. doi:10.1371/journal.pone.0016262.

Gury J, Seraut H, Tran NP, Barthelmebs L, Weidmann S, Gervais P, Cavin JF (2009) Inactivation of PadR, the repressor of the phenolic acid stress response, by molecular interaction with Usp1, a universal stress protein from Lactobacillus plantarum, in Escherichia coli. Appl Environ Microbiol 75:5273-5283. doi:10.1128/AEM.00774-09.

Hagihara H, Hatada Y, Ozawa T, Igarashi K, Araki H, Ozaki K, Kobayashi T, Kawai S, Ito S (2003) Oxidative stabilization of an alkaliphilic Bacillus a-amylase by replacing single specific methionine residue by site-directed mutagenesis. J Appl Glycosci 50:367-372

Hagihara H, Hayashi Y, Endo K, Igarashi K, Ozawa T, Kawai S, Ozaki K, Ito S (2001) Deduced amino-acid sequence of a calcium-free a-amylase from a strain of Bacillus. Implications from molecular modeling of high oxidation stability and chelator resistance of the enzyme. Eur J Biochem 268:3974-3982. doi:10.1046/j.1432-1327.2001.02308.x.

Huang HK, Tokashiki M, Maeno S, Onaga S, Taira T, Ito S (2011) Purification and properties of phenolic acid decarboxylase from Candida guilliermondii. J Ind Microbiol Biotechnol. doi:10.1007/s10295-011-0998-4

Huang Z, Dostal L, Rosazza JP (1994) Purification and characterization of a ferulic acid decarboxylase from Pseudomonas fluorescens. J Bacteriol 176:5912-5918

Kabsch W, Sander C (1983) Dictionary of protein secondary structure: pattern recognition of hydrogen-bonded and geometrical features. Biopolymers 22:2577-2637. doi:10.1002/bip.360221211.

Kurtzman CP, Suzuki M (2010) Phylogenetic analysis of ascomycete yeasts that form coenzymeQ-9 and the proposal of the new genera Babjeviella, Meyerozyma, Millerozyma, Priceomyces, and Scheffersomyces. Mycoscience 51:2-14. doi:10.1007/s10267-009-0011-5. 
Landete JM, Rodríguez H, Curiel JA, de las Rivas B, Mancheño JM, Muñoz R (2010) Gene cloning, expression, and characterization of phenolic acid decarboxylase from Lactobacillus brevis RM84. J Ind Microbiol Biotechnol 37:617-624. doi:10.1007/s10295-010-0709-6.

Mathew S, Abraham TE (2004) Ferulic acid: an antioxidant found naturally in plant cell walls and feruloyl esterases involved in its release and their applications. Crit Rev Biotechnol 24:59-83. doi:10.1080/07388550490491467.

Mathew S, Abraham TE (2006) Bioconversions of ferulic acid, a hydroxycinnamic acid. Crit Rev Microbiol 32:115-125. doi:10.1080/10408410600709628.

Mukai N, Masaki K, Fujii T, Kawamukai M, lefuji H (2010) PAD1 and FDC1 are essential for the decarboxylation of phenylacrylic acids in Saccharomyces cerevisiae. J Biosci Bioeng 109:564-569. doi:10.1016/j.jbiosc.2009.11.011.

Nonaka T, Fujihashi M, Kita A, Hagihara H, Ozaki K, Ito S, Miki K (2003) Crystal structure of calcium-free a-amylase from Bacillus sp. strain KSM-K38 (AmyK38) and its sodium ion binding sites. J Biol Chem 278:24818-24824. doi:10.1074/ jbc.M212763200.

Nonaka T, Fujihashi M, Kita A, Saeki K, Ito S, Horikoshi K, Miki K (2004) The crystal structure of an oxidatively stable subtilisin-like alkaline serine protease, KP-43, with a C-terminal $\beta$-barrel domain. J Biol Chem 279:47344-47351. doi:10.1074/jbc.M409089200.

Oelofse A, Pretorius IS, du Toit M (2008) Significance of Brettanomyces and Dekkera during winemaking: a synoptic review. S Afr J Enol Vitic 29:128-144

Pereira RS, Mussatto SI, Roberto IC (2011) Inhibitory action of toxic compounds present in lignocellulosic hydrolysates on xylose to xylitol bioconversion by Candida guilliermondii. J Ind Microbiol Biotechnol 38:71-78. doi:10.1007/ s10295-010-0830-6.

Priefert H, Rabenhorst J, Steinbüchel A (2001) Biotechnological production of vanillin. Appl Microbiol Biotechnol 56:296-314. doi:10.1007/s002530100687.

Rodríguez H, Angulo I, de Las Rivas B, Campillo N, Páez JA, Muñoz R, Mancheño JM (2010) p-Coumaric acid decarboxylase from Lactobacillus plantarum: structural insights into the active site and decarboxylation catalytic mechanism. Proteins 78:1662-1676

Saeki K, Ozaki K, Kobayashi T, Ito S (2007) Detergent alkaline proteases: enzymatic properties, genes, and crystal structures. J Biosci Bioeng 103:501-508. doi:10.1263/jbb.103.501.

Sáez JS, Lopes CA, Kirs VC, Sangorrín MP (2010) Enhanced volatile phenols in wine fermented with Saccharomyces cerevisiae and spoiled with Pichia guilliermondii and Dekkera bruxellensis. Lett Appl Microbiol 51:170-176

Sali A, Blundell TL (1993) Comparative protein modeling by satisfaction of spatial restraints. J Mol Biol 234:779-815. doi:10.1006/jmbi.1993.1626.

Smit A, Cordero Otero RR, Lambrechts MG, Pretorius IS, van Rensburg P (2003) Enhancing volatile phenol concentrations in wine by expressing various phenolic acid decarboxylase genes in Saccharomyces cerevisiae. J Agric Food Chem 51:4909-4915. doi:10.1021/jf026224d.

Stead D (1995) The effect of hydroxycinnamic acids and potassium sorbate on the growth of 11 strains of spoilage yeasts. J Appl Microbiol 78:82-87. doi:10.1111/j.1365-2672.1995.tb01677.x.

Steers E Jr, Craven GR, Anfinsen CB (1965) Evidence for nonidentical chains in the $\beta$-galactosidase of Escherichia coli K12. J Biol Chem 240:2478-2484

Thompson JD, Gibson TJ, Plewniak F, Jeanmougin F, Higgins DG (1997) The Clustal_X windows interface: flexible strategies for multiple sequence alignment aided by quality analysis tools. Nucl Acids Res 25:4876-4882. doi:10.1093/nar/25.24.4876.

Thurston PA, Tubb RS (1981) Screening yeast strains for their ability to produce phenolic off-flavours: a simple method for determining phenols in wort and beer. J Inst Brew 87:177-179

Tran NP, Gury J, Dartois V, Nguyen TKC, Seraut H, Barthelmebs L, Gervais P, Cavin JF (2008) Phenolic acid-mediated regulation of the padC gene, encoding the phenolic acid decarboxylase of Bacillus subtilis. J Bacteriol 190:3213-3224. doi:10.1128/JB.01936-07.

Uchiyama H, Hashidoko Y, Kuriyama Y, Tahara S (2008) Identification of the 4hydroxycinnamate decarboxylase (PAD) gene of Klebsiella oxytoca. Biosci Biotechnol Biochem 72:116-123. doi:10.1271/bbb.70496.

Zago A, Degrassi G, Bruschi CV (1995) Cloning, sequencing, and expression in Escherichia coli of the Bacillus pumilus gene for ferulic acid decarboxylase. Appl Environ Microbiol 61:4484-4486

doi:10.1186/2191-0855-2-4

Cite this article as: Huang et al:: An endogenous factor enhances ferulic acid decarboxylation catalyzed by phenolic acid decarboxylase from

Candida guilliermondii. AMB Express 2012 2:4.

\section{Submit your manuscript to a SpringerOpen ${ }^{\circ}$ journal and benefit from:}

- Convenient online submission

- Rigorous peer review

- Immediate publication on acceptance

- Open access: articles freely available online

- High visibility within the field

- Retaining the copyright to your article

Submit your next manuscript at $\gg$ springeropen.com 